\title{
The relationship between urban form and mode choice in US and Mexican cities: A comparative analysis of workers' commutes
}

\author{
Erick Guerra \\ University of Pennsylvania \\ erickg@upenn.edu
}

\author{
Meiqing Li \\ University of California, Berkeley \\ meiqing@berkeley.edu
}

\begin{abstract}
This paper examines empirical relationships among commuters' mode choice, metropolitan urban form, and socioeconomic attributes in the 100 largest urban areas in the United States and Mexico. Fitting multinomial logit models to data for more than 5 million commuters and their home urban area, we find several consistent relationships and several important differences in relationships among urban form and travel behavior. In both countries, urban residents living in housing types associated with more centrally located housing in more densely populated urban areas with less roadway are less likely to commute by private vehicle than similar residents in other housing types and other urban areas. In addition to some differences in the strength, significance, and signs of several predictor variables, we find large differences in elasticity estimates across contexts. In particular, the US's high rates of driving and generally car-friendly urban form mean that even dramatic shifts in urban form or income result in only small predicted changes in the probability of commuting by private vehicle. We conclude that land use and transportation policies likely have a more substantial role in shaping commute patterns in countries like Mexico than in countries like the US.
\end{abstract}

\section{Article history:}

Received: May 5, 2020

Received in revised form:

October 22, 2020

Accepted: December 10, 2020

Available online: April 9, 2021

\section{Introduction}

Although empirical research tends to emphasize the identification of generalizable relationships, the effects of transportation and land-use policies vary across people, place, and time. Geographic, social, and economic context shapes the outcomes of transportation policies and influences the relationships between urban form, transportation infrastructure, and travel behavior. While aggregate comparisons across cities and countries are common (Ingram \& Liu, 1999; McIntosh, Trubka, Kenworthy, \& Newman, 2014; Newman \& Kenworthy, 1989; Pucher, Dill, \& Handy, 2010), empirical studies of the relationship between the built environment and travel behavior at the correct ecological unit of analysisthe household or individual - tend to focus on just one metropolitan area or a single wealthy country, such as the US or the Netherlands (for an overview, see Ewing \& Cervero, 2010, 2001; Stevens, 2017). The single metropolitan areas, moreover, are most likely to be large, dense metropolitan areas, like San Francisco, Los Angeles, Mexico City, Hong Kong, or Boston. In Latin America, studies outside of the largest capital cities are particularly rare (de Vasconcellos, 2005; Guerra, Caudillo, Monkkonen, \& Montejano, 2018; Jaramillo, Lizárraga, \& Grindlay, 2012). Studies across smaller metropolitan areas in multiple countries are even rarer.

Copyright 2021 Erick Guerra \& Meiqing Li

http://dx.doi.org/10.5198/jtlu.2021.1789

ISSN: 1938-7849 | Licensed under the Creative Commons Attribution - Noncommercial License 4.0

The Journal of Transport and Land Use is the official journal of the World Society for Transport and Land Use (WSTLUR) and is published and sponsored by the University of Minnesota Center for Transportation Studies. 
In this paper, we examine empirical relationships between commuters' mode choice, metropolitan urban form, transportation infrastructure, and socioeconomic attributes for a sample of more than five million commuters in the hundred largest urban areas in both the United States and Mexico. Together, these workers represent roughly two-thirds and four-fifths of all commuters in the US and Mexico. We fit multinomial logit models to predict individual commuters' probability of traveling to work by private car, transit, or a non-motorized mode based on individual-level commuter data and metropolitan-level data about urban form and transportation infrastructure.

Better understanding the relationship between urban form, socioeconomic attributes, and workers' commute behavior across multiple urban areas in multiple countries can help shed light on the strength and relative importance of factors correlated with commuter mode choice, as well as their consistency and the role of regional and social context. Mexico's urban workers live in households with a sixth of the income of their US counterparts. They also live in six times more densely populated neighborhoods and have substantially better transit options. We focus our analysis and discussion on the relative importance of transportation supply, household income, and urban form in shaping the radically different commute patterns seen across the US and Mexico.

Our study makes three primary contributions to the land-use and transportation literature. First, it is one of only a handful of papers to examine individual-level travel behavior across multiple cities in more than one country. Individuals make choices about travel behavior and are thus the correct unit of analysis for studying how differences in urban form, transportation infrastructure, and social context contribute to differences in travel behavior. Findings thus contribute to the growing body of empirical research on the relationship between urban form, transport supply and travel behavior across cities within a country (Bento, Cropper, Mobarak, \& Vinha, 2005; Ewing, Hamadi, Gallivan, Nelson, \& Grace, 2014; Guerra et al., 2018; Sun, He, Zhang, \& Wang, 2016; Sun, Zhang, He, \& Wang, 2017; Yang, French, Holt, \& Zhang, 2012; Zhu, Li, Liu, Chen, \& Zeng, 2017) and how these relationships may vary across cities and regions in different countries (Feng, Dijst, Prillwitz, \& Wissink, 2013; Giuliano \& Dargay, 2006; Giuliano \& Narayan, 2003; Tana, Kwan, \& Chai, 2016; Zhang, 2004).

Second, our study offers insight into the nature of the relationship between socioeconomic variables, urban form, and travel behavior. If relationships between income, urban form, and commute patterns are consistent across urban areas and commuters in two substantially different contexts, then they are likely consistent across a variety of contexts. Where relationships are inconsistent, findings provide insight into how context helps to shape relationships between urban form, commuters, and commute patterns. For example, Mexico's urban commuters may be substantially more likely to change travel behavior in response to differences in income, urban form, or transportation supply than in the US. A large share of Mexico's urban population commutes by transit (50.3\%), private vehicle (31.2\%), and active modes (18.4\%). This suggests that the attractiveness of the different modes of travel are relatively close and that small changes in the cost or convenience of any given mode can potentially have large impacts on travel behavior. In the US, where $90 \%$ of workers commute by car, even radical changes to the attractiveness of any mode will likely only have small impacts on aggregate mode choice. Doubling the numbers of workers who walk or bike to work, for example, would only reduce driving commutes by around $3.6 \%$.

Third, by providing a consistent analysis across two substantially different contexts, our study helps shed light into the transferability of transportation and land-use policies across contexts. Despite the US's somewhat exceptional commute patterns and urban form—only a handful of other countries look like the US in this respect-a disproportionate amount of research into land use and transportation comes from US urban areas. Just five studies from the 62 included in most cited literature review on the relationship between travel behavior and the built environment (Ewing \& Cervero, 2010) use data 
from outside of the US. Just one of these studies, an earlier conference paper of Zegras' (2010) study of Santiago de Chile, is from a Latin American context. None are from smaller Latin American cities. If relationships vary substantially across the US-Mexico border, drawing on a US-dominated body of literature to shape public policy may be ineffective, particularly in the many cities of Latin America, Asia, and Africa that have lower levels of income, motorization, and suburbanization than Mexico's urban areas.

The remainder of this paper is organized as follows. First, we describe our general research approach, data sources, and hypotheses. Second, we report the results of four commute mode choice models. Next, we present the results of several simulations of the collective relationship between multiple measures of urban form and commute mode choice. Last, we conclude with a discussion of our main takeaways, study limitations, and opportunities for future research.

\section{Research approach}

We predict commuter mode choice as a function of individual-level measures of socioeconomic attributes and urban-level measures of urban form. This general estimation framework is common in studies of urban form and travel behavior across multiple cities in one or more countries (Bento et al., 2005; Giuliano \& Dargay, 2006; Guerra et al., 2018; Sun et al., 2017; Yang, Wang, Bai, \& Han, 2017). There is a broad and deep academic literature on the relationship between the built environment and travel behavior, with multiple review papers and several empirical meta-analyses (Ewing \& Cervero, 2010; Stevens, 2017). Within this literature, measures of the built environment range substantially and include dummy variables indicating whether a development is urban or suburban, metropolitan-level measures of urban form, and neighborhood measures at residents' home locations, as well as the origin and destination of specific trips. We use the term urban form to emphasize that our study relies on metropolitanlevel measures, rather than measures of the local built environment. There is an equally deep and broad literature on urban form more generally and Reis, Silva, and Pinho (2016) identify over a hundred spatial measures in the existing literature. We focus our analysis on measures commonly associated with mode choice and travel behavior, such as density, diversity of activities, design, and transportation infrastructure (Cervero \& Kockelman, 1997; Ewing \& Cervero, 2010).

Mexican urban areas are highly multimodal with substantial and continuous variation in modal importance (Figure 1). Even in La Paz, the most car-reliant urban area, $40 \%$ of commuters walk, bike, or take transit. In the US, by contrast, nearly everyone drives to work, with just a few metropolitan areas where less than $90 \%$ of commutes are by car. Income almost certainly plays a role in national differences as well. Mexican commuters have average household incomes that are around 8 times lower than American commuters ( 6 times lower after accounting for purchasing power parity). So does the built environment. Mexican urban areas are around 5 times denser than US ones on average. 


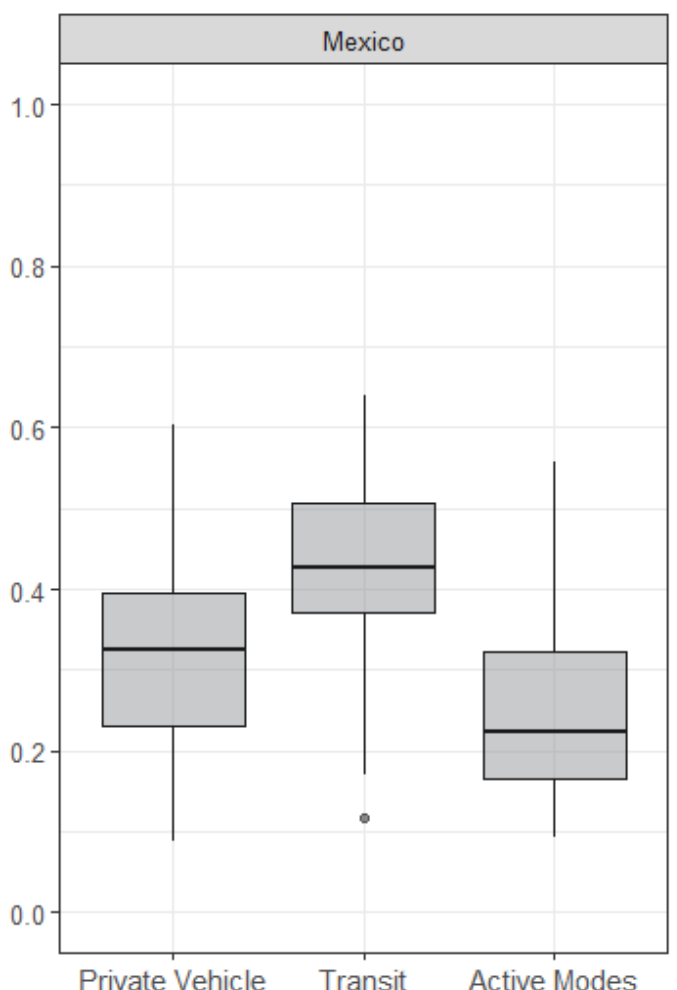

Private Vehicle Transit Active Modes

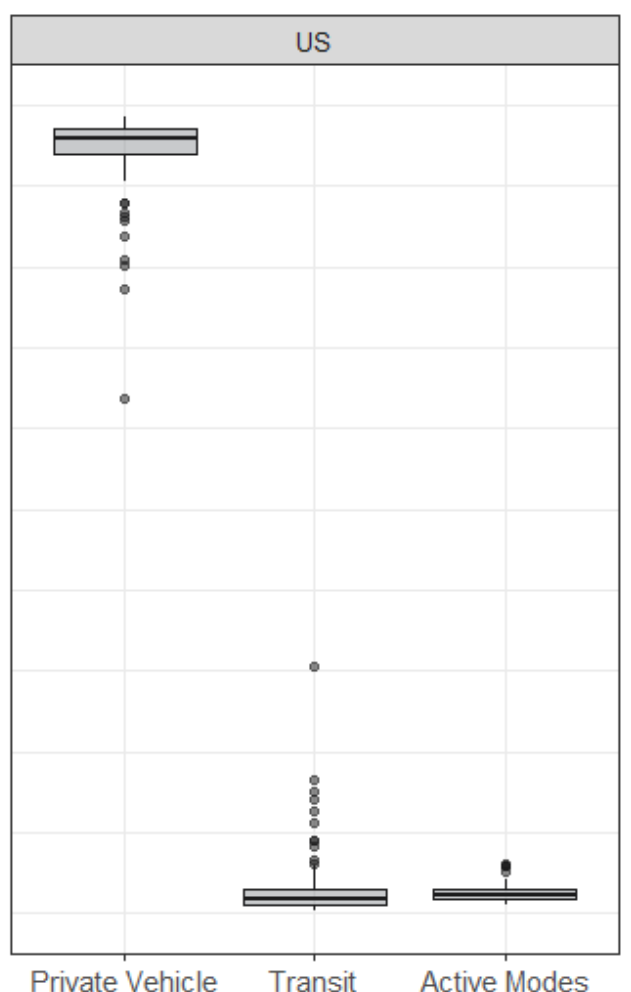

Private Vehicle Transit Active Modes

Figure 1. Distribution of commute mode share in the 100 largest urban areas in both the US and Mexico

\section{$2.1 \quad$ Data sources and measures}

Table 1 presents our data sources, definitions, and expected relationships with workers' commute mode choice. For individual and household level data, we rely on four years (2012-2015) of the American Community Survey Public Use Microdata Sample 1-year data and the 2015 Mexican Intercensal Survey (INEGI, 2015). Each of the two national surveys asks workers about their typical commute mode in the previous week. We aggregate modes into three consistent categories across the two national samples: private vehicle (including drivers and passengers of cars, trucks, vans, and motorcycles); transit (including metro, bus rapid transit, light rail, trolley, subway, worker shuttles, and taxicabs); and active travel (walking and cycling). We exclude other and unreported modes of travel, which account for less than $1 \%$ of commutes in both countries. We convert variables, such as income and highest educational attainment, into consistent units across the two national samples. We also introduce quadratic terms to age in order to account for shifts in modal preference as workers age and take the natural log of household income to reduce skewness and account for the long right-tail of wealthy households in both countries.

Urban-level measures are calculated from the 2010 US Census, 2015 5-year American Community Survey, 2010 Mexican Census, 2015 US Longitudinal Employer-Household Dynamics OriginDestination Employment Statistics, 2009 Mexican Economic Census, and 2017 OpenStreetMap data. Although the spatial measures are calculated from different years, cross-sectional variation is much more substantial than shifts in metropolitan form over the course of five years. In the US, the hundred largest urban areas are the 100 most populous metropolitan statistical areas. In Mexico, the urban areas include all 59 of the country's metropolitan areas and the 41 next largest officially designated urban areas (CONAPO, 2018). 
Table 1. Data description and expected relationships with commute mode choice

\begin{tabular}{|c|c|}
\hline Variables & Description \\
\hline \multicolumn{2}{|c|}{ Individual-level measures $^{l}$} \\
\hline $\begin{array}{l}\text { Commute mode } \\
\text { choice }\end{array}$ & $\begin{array}{l}\text { Primary means of transportation to work by } \\
\text { private vehicle (driver and passengers of cars, } \\
\text { trucks, vans, and motorcycles), transit (metro, } \\
\text { bus rapid transit, light rail, trolley, subway, } \\
\text { worker shuttle, and taxicabs) or active modes } \\
\text { (walking or cycling). }\end{array}$ \\
\hline Household income & $\begin{array}{l}\text { Log-transformation of monthly household } \\
\text { income in US dollars adjusted by purchasing } \\
\text { power parity. A dummy variable indicates miss- } \\
\text { ing income data. }\end{array}$ \\
\hline Household size & Number of persons in household \\
\hline Vehicle availability & $\begin{array}{l}\text { Whether the worker's household has a car, van, } \\
\text { or light-duty truck }\end{array}$ \\
\hline Gender & Male or female \\
\hline Age & Worker's age \\
\hline Occupation & $\begin{array}{l}\text { Worker's occupation (in agriculture, manufac- } \\
\text { turing, or service industry) }\end{array}$ \\
\hline $\begin{array}{l}\text { Highest educational } \\
\text { attainment }\end{array}$ & $\begin{array}{l}\text { Worker's highest educational attainment (less } \\
\text { than middle school, middle school, high } \\
\text { school, college and above) }\end{array}$ \\
\hline Housing type & $\begin{array}{l}\text { The type of housing the worker's household } \\
\text { lives in (single-family detached, single family } \\
\text { attached, apartment, and other) }\end{array}$ \\
\hline
\end{tabular}

Expected relationship with commute choice

Low income groups are more likely to commute by transit or non-motorized modes.

Offsets household income, but larger households may also have more complicated travel patterns better served by private vehicle.

Vehicle availability indicates preference for driving and makes private vehicle commute easier.

Men are more likely to commute by private modes including vehicles and bicycles.

Younger people are more likely to take transit, walk or bike.

Occupations better served by transit, such as services in the US, are more likely to have transit commuters. Suburban-oriented occupations are more likely to indicate private vehicle commutes.

Highest educational attainment is positively associated with people's likelihood to drive.

Housing type is considered as a proxy for local built environment and relates to commute mode choice in that single-family detached housing is mostly likely associated with driving while apartment is more likely associated with commuting by transit, walking or biking.

\section{Urban-level measures ${ }^{2}$}

Population density

Number of people per hectare weighted by the number of people in each census tract within that urban area

Jobs-population imbalance (Gini)

Jobs-area imbalance (Gini)

Gini index of the percentage of jobs relative to the percentage of population in each census tract within that urban area; 1: perfect imbalance, 0 : perfect balance.

Gini index of the percentage of jobs relative to the percentage of land area in each census tract within that urban area; 1 : perfect imbalance, 0 : perfect balance.

Average block length Average length of road segments within an urban area
Transit and active commutes are higher in denser urban areas.

Jobs-population imbalance is positively associated with more driving and less active commuting since commute distances tend to be longer.

Jobs-area imbalance is positively associated with higher rates of transit since more concentrated job centers are more easily served by transit.

Shorter roadway segments and smaller block sizes increase non-motorized connectivity and are more pedestrian friendly. 


\begin{tabular}{lll}
\hline Variables & Description & Expected relationship with commute choice \\
\hline $\begin{array}{l}\text { Share of road length } \\
\text { by arterial }\end{array}$ & $\begin{array}{l}\text { Percentage of road length in that urban area } \\
\text { that is arterial }\end{array}$ & $\begin{array}{l}\text { Roadway supply is positively associated with } \\
\text { car use. The share of commuting by private } \\
\text { vehicle is higher in urban areas with more road- } \\
\text { by highway }\end{array}$ \\
$\begin{array}{l}\text { Roadway length per } \\
\text { capita }\end{array}$ & $\begin{array}{l}\text { Percentage of road length in that urban area } \\
\text { that is highway } \\
\text { Kilometers of all roadway (highway, arterial, } \\
\text { and local roads) divided by total population }\end{array}$ & $\begin{array}{l}\text { higher shares of arterials may also be conducive } \\
\text { to transit use. }\end{array}$ \\
\hline
\end{tabular}

Notes: 1. Commute mode choice, demographic, and household variables from American Community Survey (ACS) and Mexican Intercensal Survey. 2. Measures of urban form calculated from 2010 US and Mexico Decennial Censuses, 2015 US Longitudinal Employer-Household Dynamics Origin-Destination Employment Statistics, 2009 Mexican Economic Census, and OpenStreetMap.

Population density reflects the census-tract-level population density for urban residents on average. Mexico's census-tract equivalent, the Ageb, is smaller than a US census tract and typically contains around 2,500 people compared to 4,000 people in a US census tract. Jobs-population imbalance measures the distribution of jobs relative to that of people across all census tracts as a Gini coefficient. A score of one indicates a perfect imbalance with all jobs and residents occurring in different tracts. A score of zero indicates that jobs and people are proportionately distributed across tracts. The jobs-area imbalance Gini coefficient measures the spatial concentration of jobs. A score approaching one indicates a monocentric city with all jobs in just a few small census tracts. A score of zero indicates that jobs are equally spread by land area across census tracts. We calculate average block length using OSMnx (Boeing, 2017). Urban areas with shorter road segments tend to have smaller, more pedestrian friendly block sizes.

Our final dataset emphasizes consistency across measurements and the avoidance of multicollinearity in measures of urban form. For example, we do not include measures of ethnicity or national origin. Although common in studies from the US (Blumenberg \& Pierce, 2014; Hu, 2014), equivalent measures are rare in Latin American contexts and generally excluded from travel behavior models (Guerra et al., 2018; Suárez, Murata, \& Delgado, 2016; Suárez \& Delgado, 2009). Similarly, we exclude measures of whether someone works in the informal sector, despite featuring in studies that predict travel behavior in Mexico (Suárez \& Delgado, 2009; Guerra et al., 2018; Suárez et al., 2016). In terms of collinearity, we exclude measures of urban form with relatively high correlations with other variables. For example, we do not include job density, measures of mass transit supply, or total population, because they are strongly correlated with population density in one or both countries. Despite the substantial number of commuters in the dataset, each country only has one hundred observations at the scale of the urban area. Summarizing problems with overfitting, Babyak (2004) suggests a minimum of 10-to-15 observations per predictor variable - a minimum that increases with the total number and strength of correlations across predictors. Thus, we choose a parsimonious and relatively uncorrelated set of urban-scale measures. Metropolitan population density is thus best interpreted as an overall proxy for multiple measures of dense urban form that reduce the utility of driving relative to transit and non-motorized modes.

\subsection{Data summary}

Table 2 summarizes the final data sample used in our models predicting commuter mode choice in the hundred largest urban areas in the US and Mexico. Workers from Mexico's urban areas tend to rely on a far greater mixture of transportation modes to get to work than those in US urban areas. In the Mexico sample, $28 \%$ of workers commute to work by private vehicle, $49 \%$ by transit, and $23 \%$ by foot or bike. In the US sample, by contrast, fully $90 \%$ commute to work by car, $7 \%$ by transit, and just $3 \%$ by foot 
or bike. Relative to US workers, Mexico's workers are more likely to be male, have lower educational attainment, work in manufacturing or agriculture, lack access to a private vehicle, and be less wealthy. Accounting for purchasing power parity, workers in the Mexico sample live in larger households with a sixth of the income of workers' households in the US sample. Workers in the Mexico sample also tend to live in urban areas that are more densely populated with substantially less roadway per capita, less spatial separation between jobs and residents, and more strongly concentrated job centers. The average neighborhood population density for residents in Mexican urban areas is three times higher than for residents in US urban areas. In terms of transportation supply, US urban areas have much more substantial road networks than Mexican ones with six times as much highway, arterial, and local roadway per capita. The average block is also substantially longer in the US than in Mexico, suggesting less pedestrian-friendly block sizes and fewer interruptions to high-speed traffic.

\subsection{Model specification}

We estimate multinomial logit models in the mlogit package (Croissant, 2019) in R (R Core Team, 2018) to predict workers' commute mode choice as a function of metropolitan urban form, road supply, and the individual attributes of commuters in the 100 largest urban areas in both the US and Mexico. We also estimate average individual elasticities using sample enumeration (Train, 2009, Chapter 2.6.1) to account for sample weights and provide consistent estimates of the magnitude of the relationship between urban form, income, and commute mode choice across the two data samples. 
Table 2. Summary statistics

\begin{tabular}{|c|c|c|c|c|}
\hline \multirow[b]{2}{*}{ Variables } & \multicolumn{2}{|c|}{ Mexico $(\mathrm{N}=2,435,133)$} & \multicolumn{2}{|c|}{ US $(\mathrm{N}=3,276,640)$} \\
\hline & Mean & Std. Dev. & Mean & Std. Dev. \\
\hline \multicolumn{5}{|l|}{ Commute mode share } \\
\hline Private vehicle & $27.7 \%$ & & $89.8 \%$ & \\
\hline Transit & $49.3 \%$ & & $7.1 \%$ & \\
\hline Non-motorized & $22.9 \%$ & & $3.1 \%$ & \\
\hline \multicolumn{5}{|l|}{ Individual-level measures } \\
\hline Monthly household income (USD PPP') & 1,480 & 2,047 & 9,170 & 8,234 \\
\hline Income unreported $^{2}$ & $4.6 \%$ & & $0 \%$ & \\
\hline Household size & 4.4 & 2.2 & 3.1 & 1.6 \\
\hline Vehicle availability & $48.1 \%$ & & $95.3 \%$ & \\
\hline Male & $64.3 \%$ & & $52.2 \%$ & \\
\hline Age & 38 & 13 & 43 & \\
\hline \multicolumn{5}{|l|}{ Occupation } \\
\hline Manufacturing/construction/transport & $28.9 \%$ & & $18.0 \%$ & \\
\hline Services/military & $65.5 \%$ & & $81.5 \%$ & \\
\hline Agriculture & $5.1 \%$ & & $0.1 \%$ & \\
\hline Unreported/missing & $0.6 \%$ & & $0.0 \%$ & \\
\hline \multicolumn{5}{|l|}{ Highest educational attainment } \\
\hline Less than middle school & $29.1 \%$ & & $2.4 \%$ & \\
\hline Middle school & $31.3 \%$ & & $6.3 \%$ & \\
\hline High school & $23.2 \%$ & & $43.5 \%$ & \\
\hline College degree or higher & $23.5 \%$ & & $47.8 \%$ & \\
\hline \multicolumn{5}{|l|}{ Housing type } \\
\hline Single-family detached & $73.6 \%$ & & $68.4 \%$ & \\
\hline Single-family attached & $16.0 \%$ & & $7.2 \%$ & \\
\hline Apartment & $9.3 \%$ & & $22.0 \%$ & \\
\hline Other housing type & $1.0 \%$ & & $2.5 \%$ & \\
\hline \multicolumn{5}{|l|}{ Urban-level measures } \\
\hline Population density (people per hectare) & 99.17 & 39.47 & 29 & 30.74 \\
\hline Jobs-population imbalance (Gini) & 0.24 & 0.08 & 0.48 & 0.05 \\
\hline Jobs-area imbalance (Gini) & 0.47 & 0.04 & 0.38 & 0.08 \\
\hline Average block length (m) & 136.44 & 36.56 & 250.06 & 62.11 \\
\hline Share of road length by arterial & 0.12 & 0.04 & 0.09 & 0.02 \\
\hline Share of road length by highway & 0.08 & 0.02 & 0.13 & 0.03 \\
\hline Roadway length per capita (km per 100 people) & 0.26 & 0.1 & 1.58 & 0.87 \\
\hline
\end{tabular}

Notes: 1 . Mexican pesos converted to US dollars using exchange rate and accounting for purchasing power parity. 2. For individuals with no income or occupation data, we set income to zero and add dummy variables indicating missing data. 
Although we do not explicitly account for residential self-selection beyond a robust set of socioeconomic control variables-for a review of the problems and potential empirical solutions, see (Cao, Mokhtarian, \& Handy, 2009; Handy, Cao, \& Mokhtarian, 2005; Mokhtarian \& Cao, 2008)—workers are far more likely to choose residential locations within a metropolitan based on travel preferences than to choose across metropolitan areas. Unlike many studies of commute mode choice, our estimates do not include estimates of the travel time or travel cost of alternative modes. Thus, our estimates of the relationships between urban form, socioeconomic variables, and commute mode include any intermediary relationships that may occur through relationships to travel times and travel costs. For example, denser urban areas likely decrease car speeds and increase the probability that homes and workplaces are close enough for a walking commute. Similarly, wealthier and better educated commuters are more likely to be able to select into home-work pairs that are suited to their preferred travel mode in terms of travel time and cost. To account for correlated error terms within urban areas, we present Liang and Zeger (1986) clustered standard errors. We also estimated models using binary logit models of each mode against the reference mode (private vehicle). This Begg and Gray (1984) approximation produces more conservative estimates of standard errors than a multinomial logit model and allowed us to introduce random intercepts for each urban area using a multilevel modeling structure. This procedure produced consistent results with the reported multinomial logit models with clustered standard errors.

\section{Results}

Table 3 presents the results of the models predicting the probability of commuting by transit and nonmotorized modes relative to commuting by private vehicle in Mexico (Model 1) and the US (Model 3). We discuss Model 2 and Model 4, which include a dummy variable for whether the household has a private car, truck, or van available to the household, in Section 3.3. We converted several predictor variables so that the statistically significant parameter estimates are closer to one or negative one. This facilitates model convergence and makes it easier to read the model outputs. For example, population density is presented in terms of hundreds per hectare and Gini coefficients range from 0 to 100 instead of 0 to 1 . Coefficient estimates have direct interpretations in terms of the utility associated with each

mode. For example, a one unit increase in hundreds of people per hectare is associated with 0.273 and 2.068 increase in the utility of commuting by transit in Mexico and the US. Taking the exponent of the coefficient makes the coefficient interpretable as an odds ratio. For an average commuter in Mexico and the US, these increases in utility correspond with a 31\% and $691 \%$ increase in the odds of choosing transit over a private vehicle. 


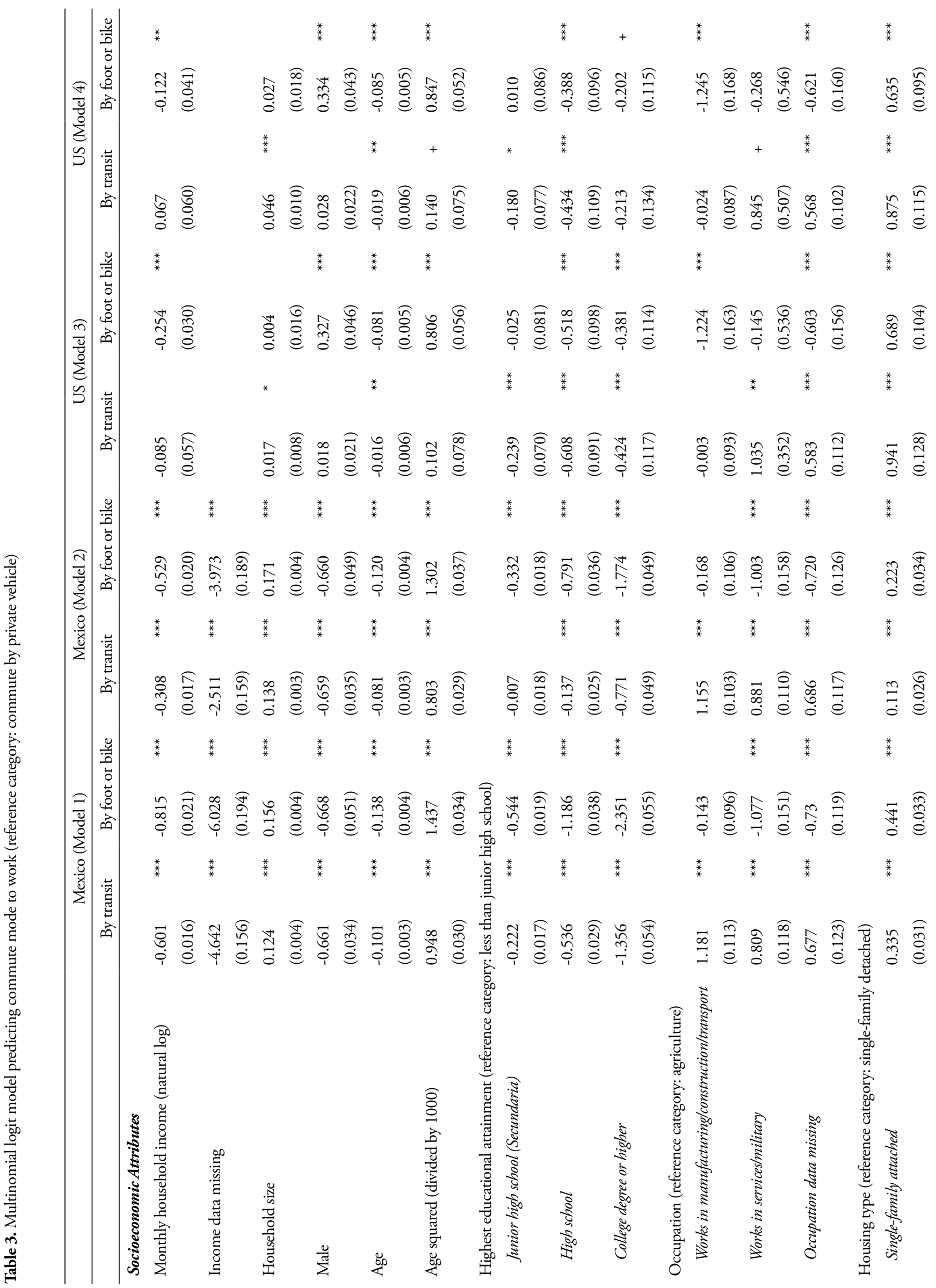




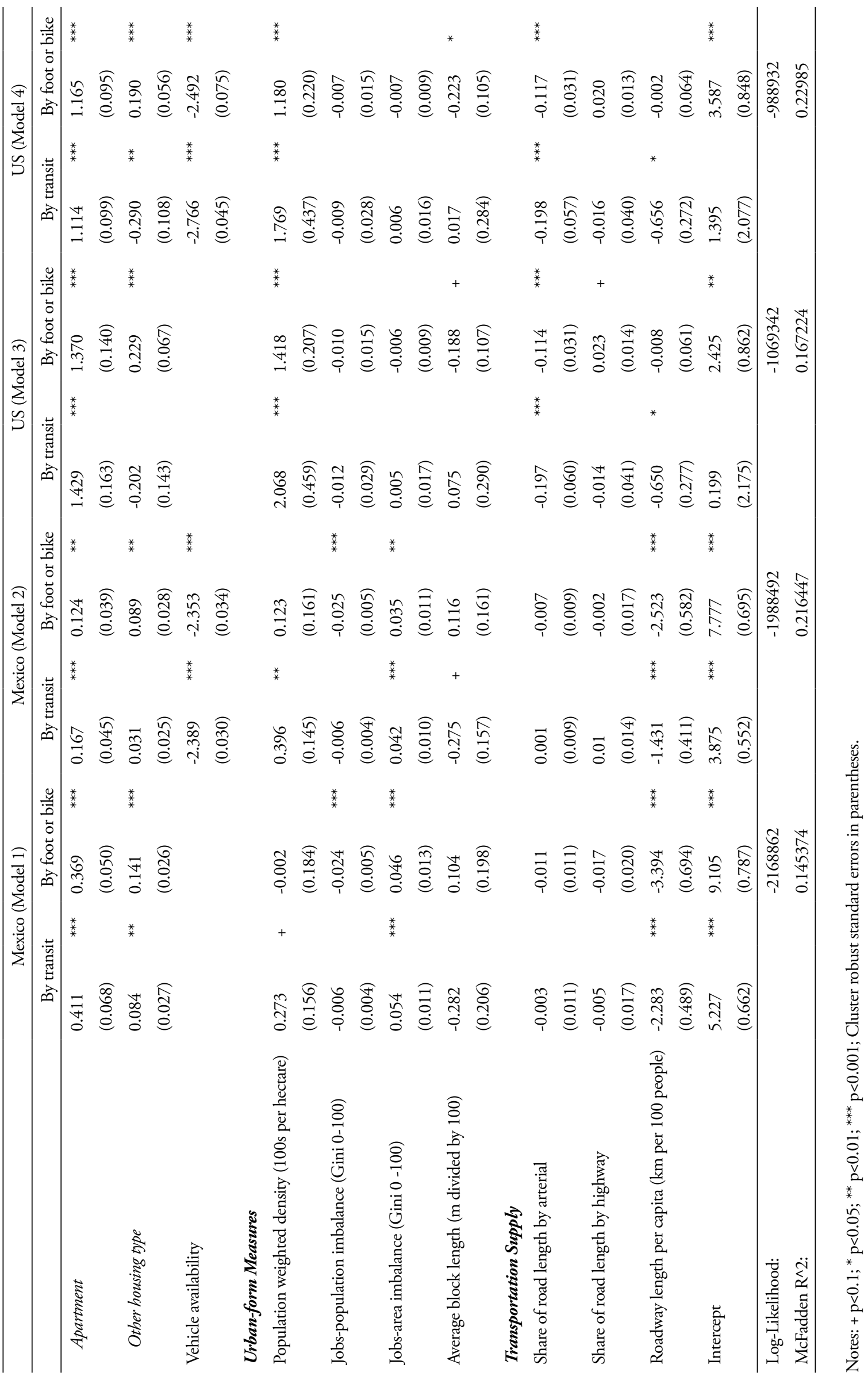


Neither utility nor odds ratios are directly comparable across the samples, however. Effect sizes depend on the relative attractiveness of the alternative modes and the distributions of the dependent and independent variables. For example, increasing population density by 100 people per hectare roughly doubles population density in the Mexico sample and roughly quadruples it for the US sample. Applying Ewing and Cervero's (2010, p. 273) elasticity formula to the average commuter, a doubling of population density corresponds with a $14 \%$ increase in the probability of commuting by transit in Mexico and $55 \%$ increase in the US. Applying the same estimate to the probability of commuting by private vehicle, the elasticity shifts to -0.20 in Mexico, where more workers travel by transit than car, and -0.06 in the US, where nine in ten workers commute by car. We report parameter estimates in terms of utility instead of odds-ratios to avoid possible misinterpretations about the relative strength of parameter estimates across the two national samples. Section 4 presents more directly comparable elasticity estimates.

\subsection{Socioeconomic attributes and commute mode choice}

In the US and Mexico's largest urban areas, higher income, higher educational attainment, and smaller household sizes tend to be associated with a higher probability of commuting by private vehicle and a lower probability of commuting by transit or active modes. The relationship between income and commuting by transit instead of private vehicle, however, is not statistically significant in the US. This may reflect the relatively wealthy rail commuters that make up a substantial share of transit commuters in large US urban areas. For example, rail commuters in the New York metropolitan area make up nearly three quarters of New York's transit commuters and live in households that earn an average of $\$ 127,000$ per year. Across the entire US sample, rail commuters live in households that earn 1.6 times more than bus commuters.

The probability of commuting by private vehicle follows a similar pattern with age in both countries. In the US, men are more likely than women to commute by active modes, while in Mexico the opposite relationship holds. In terms of employment, service-sector workers in both the US and Mexico are more likely to commute by transit or active modes relative to agricultural workers. In Mexico, working in manufacturing is positively associated with workers' likelihood of taking transit, whereas in the US it is negatively associated. This may reflect the greater availability of workplace transit shuttles, better suburban transit services, or denser concentrations of manufacturing in Mexican cities than US ones.

Thus, while we tend to find commonality in many of the mode choice predictors in terms of the direction and statistical significance of socioeconomic predictor variables, there are several notable differences that may relate to culture or geography. In the US, for example, higher income is not statistically significantly associated with differences in the probability of commuting by transit relative to private vehicle. In Mexico, women appear to have less opportunity to commute by private vehicle than men. In Mexico, existing transit services appear to do a relatively decent job of serving manufacturing and construction jobs.

\subsection{Urban form and commute mode choice}

As with socioeconomic attributes, there are several notable similarities between how measures of metropolitan urban form correlate with commute mode choice in both US and Mexican urban areas. Across national borders, urban residents are less likely to commute to work by private vehicle in densely populated urban areas with less roadway per capita and smaller block sizes. Workers living in attached homes and multifamily buildings are also less likely to commute by private vehicle than workers living in detached single-family homes. Although somewhat of a crude proxy for location within an urban area, this finding suggests that workers living in more central locations with higher neighborhood densities are 
more likely to get to work by transit or active modes than those living in more suburban neighborhoods.

There are also several notable differences in the relationship between urban form and commute mode choice. At the metropolitan scale, jobs-population imbalance and jobs-land imbalance are statistically associated with mode choice in Mexico but not in the US. In Mexico, this finding suggests that more diverse land uses and more monocentric urban form lend themselves to greater use of transit and active modes. In the US, these features do not appear to covary with mode choice at the metropolitan scale, though the literature suggests that land-use diversity likely relates to mode choice at the neighborhood level. This inconsistency may relate to the scale of the urban measurements, the small number of urban-level observations, or other factors.

Another notable difference is that population density is significantly correlated with workers choosing active modes over private vehicles in the US, but not in Mexico. In Mexico, utilitarian walking and cycling occur frequently in suburban and rural environments and may be less responsive to differences in metropolitan form. In metropolitan Mexico City, for example, $20 \%$ of suburban workers commute by non-motorized modes compared to $16 \%$ in the city proper. Nevertheless, active commuting does decrease in urban areas with more roadway per capita. Finally, living in an apartment or an attached home has a similar relationship to commute choice in Mexico, but parameter estimates for living in an apartment are nearly twice as strong as parameter estimates for living in an attached home in the US. This may suggest that the most central locations are particularly important for commuter mode choice in US cities. Since housing type corresponds differently to different neighborhood types across and within national and metropolitan boundaries, however, results should be interpreted with caution. For example, many of Mexico City's suburban neighborhoods are as dense and diverse as more centrally located ones (Guerra, 2014a, 2014b). The highest density census tracts in Mexican urban areas are often in suburban neighborhoods comprised primarily of small, single-family homes, whether informally built over time or constructed as part of Mexico's national low-to-moderate income housing construction program, which supplanted informal construction as the primary producer of new housing units two decades ago (Monkkonen, 2011). Moreover, the definitions of "casa única en el terreno" and "casa que comparte terreno con otra(s)" may not as clearly distinguish between single-family detached and attached homes as do the US census definitions. As a result, Mexican households that we assigned to single-family homes may live in attached row homes, which are a particularly common style of housing in urban Mexico.

\subsection{Automobile availability}

Workers with a private vehicle in the household are less likely to commute by transit or active modes than workers without a private vehicle in the US and Mexico. Including controls for vehicle availability tends to reduce the strength and statistical significance of socioeconomic predictors, such as income and educational attainment. For example, including vehicle availability in the Mexico models roughly halves the strength of the relationship between household income and the probability of commuting by transit instead of car from - 0.601 (Model 1) to - -0.308 (Model 2). In terms of urban form, the strength of the predictor variables remains relatively consistent, with no parameter estimates changing by more than a standard error after including vehicle availability. Wealthier and better educated commuters are more likely to have access to a private car, but the relationship between metropolitan measures of urban form and commute patterns appear to be generally consistent regardless of car availability. In the US a similar trend holds between housing type and commute patterns, although the strength of the relationship between commute mode and housing type weakens substantially and significantly in Mexico after including vehicle availability. For example, a typical Mexican commuter in an apartment has $51 \%$ higher odds of commuting by transit instead of car relative to a typical commuter in a single-family home (Model 1). Including vehicle availability weakens the strength of this relationship to $18 \%$ higher odds (Model 2). 


\section{$4 \quad$ Inferences about the relationship between urban form and commute mode choice}

To better understand the relative and absolute strength of the estimated relationships between measures of urban form and commuting behavior in the US and Mexico, we simulate a series of behavioral responses to changes in urban form based on our model results. We use these simulations to draw inferences about how changes in population density, road networks, and other measures of urban form are likely to relate to commuter mode choice across urban areas in both countries.

\subsection{Elasticity estimates}

Table 4 presents a series of elasticity estimates generated by increasing the values of continuous predictor values by $10 \%$ and estimating the proportional sample-weighted shifts in commuters' average probability of commuting by private vehicle, transit, or active modes. We focus on three main takeaways about the absolute and relative strength of the measures of urban form in large urban areas in the US and Mexico.

Table 4. Elasticity with respect to the probability of commuting to work by private vehicle

\begin{tabular}{|c|c|c|c|c|c|c|}
\hline & & Mexico & & & US & \\
\hline Variable & $\begin{array}{l}\text { Private } \\
\text { vehicle }\end{array}$ & $\begin{array}{l}\text { Active } \\
\text { modes }\end{array}$ & Transit & $\begin{array}{l}\text { Private } \\
\text { vehicle }\end{array}$ & $\begin{array}{l}\text { Active } \\
\text { modes }\end{array}$ & Transit \\
\hline Monthly household income & 0.42 & -0.31 & -0.13 & 0.01 & -0.23 & - \\
\hline Population density & -0.14 & - & 0.14 & -0.12 & 0.29 & 0.49 \\
\hline Jobs-population imbalance & 0.18 & -0.41 & - & - & - & - \\
\hline Jobs-area imbalance & -1.58 & 0.46 & 0.83 & - & - & - \\
\hline Average block length & - & - & - & - & -0.40 & - \\
\hline Roadway per capita & 0.43 & -0.48 & -0.11 & 0.05 & - & -0.86 \\
\hline Share of road length by arterial & - & - & - & 0.17 & -0.80 & -1.46 \\
\hline
\end{tabular}

Notes: The table only includes elasticities of variables with statistically significant parameter estimates at the $95 \%$ confidence level. Estimates based on model (1) and (3) that do not control for vehicle availability.

First, the measures of urban form are relatively strong, though not always consistent, predictors of commute mode choice and more strongly associated with mode choice than household income in both the US and Mexico. In Mexico, a doubling of household income is associated with an average $42 \%$ increase in commuters' probability of commuting by car. A similar strength relationship exists with the amount of roadway per capita and the collective relationship of the other four statistically significant urban form variables. In the US, a doubling of household income is associated with a paltry $1 \%$ increase in the average probability of commuting by private vehicle. This is a substantially weaker relationship than any of the four measures of urban form associated with commuter mode choice. In a country, where most people commute to work by car, regardless of income, metropolitan urban form appears to matter a great deal more than income.

Second, there are some substantial differences in the strength and statistical significance of urban form variables in the US and Mexico. The concentration of jobs appears particularly strongly correlated with commute patterns in Mexico but not in the US. Similarly, the share of the road network that is 
an arterial road is strongly associated with commute patterns in the US but not in Mexico. Although shorter block sizes are associated with more commuting by foot or bike in both contexts, the strength and statistical significance varies by country and model specification. Only the relationships between population density, roadway per capita, and the probability of commuting by transit or active modes appear to be generally consistent across the models.

These findings suggest care be taken when generalizing results from one context to another. Neither the strength nor the statistical significance of predictor variables holds across our national samples even if the results point to the general finding that denser urban areas with less roadway tend to have less commuting by private vehicle.

Third, elasticity estimates depend substantially on the share of commuters choosing a mode and are not likely to be consistent across contexts or even modes. This is most apparent in the US sample where most commuters get to work by private vehicle. Although a doubling of residential densities in a metropolitan area corresponds with a $49 \%$ higher probability of commuting by transit and a $29 \%$ higher probability of commuting by active modes, this corresponds with a much weaker $12 \%$ decrease in the probability of commuting by private vehicle. In the case of income, although higher incomes are strongly related to a decreased probability of commuting by active modes (elasticity of -0.23 ), the probability of commuting by active modes is so low that the relationship to the probability of commuting by private vehicle is extremely weak (elasticity of 0.01 ). In Mexico, by contrast changes in income and urban form are relatively strongly and consistently associated with shifts in the probability of commuting by different modes. This suggests that aggregate mode share will be much more responsive to shifts in policy or other external factors in Mexico than in the US.

\subsection{Commute mode choice across urban areas}

In order to examine the collective predictive strength of the measures of urban form on commuter mode choice, we simulate moving our sample of residents to different urban areas and predicting aggregate commute share in those environments. Table 5 predicts aggregate mode share to work if we simulate the entire sample living in a car-friendly, average, and car-unfriendly urban area. In the US, these urban areas correspond to metropolitan Knoxville, Baltimore, and New York. Notably, these simulations leave survey respondents in their existing housing types and thus may underestimate the sum-total predictive power of urban form since New York, for example, has a much higher share of residents living in apartments and row homes than the rest of the country. Nevertheless, moving the entire sample from an average urban area like Baltimore to New York results in a substantial shift in car commuting from $93.3 \%$ to $69.7 \%$ of total commutes. The decrease comes primarily from a large shift in transit use from $3.9 \%$ to $25.0 \%$ of the total. This simulated shift provides a counterpoint to findings that individual socio-economic factors play a larger role than land use in determining commute behavior in US contexts (Boarnet \& Crane, 2001; Ewing et al., 2015; Handy, Cao, \& Mokhtarian, 2006). Residents of metropolitan New York, San Francisco, Chicago, Boston, and Philadelphia do not commute differently from the rest of the US because they are substantially different people but because they live in urban areas with substantially different urban form. Outside of the outlier metropolitan areas that are apparent in Figure 1's boxplot, however, commuter mode share budges only slightly. Moving from an average urban form, like metropolitan Baltimore, to a particularly car-friendly one, like metropolitan Knoxville, results in only a three-percentage point decrease in private vehicle commuting. Across most US metropolitan areas, therefore, socio-economic factors do appear to have a much stronger relationship with commuting than does urban form. 
Table 5. Simulated mode share based on assigning population sample to specific urban areas

\begin{tabular}{lllccc}
\hline Data Sample & Urban type & Urban example & Private vehicle & Transit & Active modes \\
\hline US population & Car friendly & Knoxville, TN & $96.6 \%$ & $1.6 \%$ & $1.8 \%$ \\
\hline & Average & $\begin{array}{l}\text { Baltimore- } \\
\text { Columbia- } \\
\text { Towson, MD }\end{array}$ & $93.3 \%$ & $3.9 \%$ & $2.8 \%$ \\
& Car unfriendly & $\begin{array}{l}\text { New York- } \\
\text { Newark-Jersey } \\
\text { City, NY-NJ-PA }\end{array}$ & $69.7 \%$ & $25.0 \%$ & $5.3 \%$ \\
\hline $\begin{array}{l}\text { Mexican popula- } \\
\text { tion }\end{array}$ & Car friendly & La Paz & $38.1 \%$ & $40.0 \%$ & $21.9 \%$ \\
\hline & Average & Querétaro & $32.3 \%$ & $48.0 \%$ & $19.8 \%$ \\
\hline Car unfriendly & Valle de México & $20.9 \%$ & $56.7 \%$ & $22.4 \%$ \\
\hline
\end{tabular}

Notes: The estimations are based on Model (1) and (3) estimates that do not control for auto ownership.

In Mexico, we predict the results of shifting the entire data sample from a typical urban area, like Queretaro, to a car-friendly (La Paz) or car-unfriendly one (Mexico City). As in the US, most of the shift comes from substitution between transit and car and the predicted commute shift from moving the sample from an average urban area to the least car-friendly one is large. Moving the sample from Queretaro to Mexico City results in a 35\% (eleven percentage point) drop in commuting by private vehicle. Unlike in the US, urban form appears to continue to play a relatively strong role in predicting commute patterns in more car-friendly urban areas as well. Moving the sample from Queretaro to La Paz corresponds with a 16\% drop in private vehicle commuting. This is unsurprising since measures of urban form and commute mode share are much more normally distributed than in the US, where just a handful of dense metropolitan areas account for most transit and non-motorized commutes. Another difference with the US is that car-friendly urban form does not appear as systematically associated with active modes in Mexico's urban areas. Roughly a fifth of the sample commutes by active modes in all three of the simulated metropolitan areas, suggesting that socioeconomic characteristics are particularly important for active modes in urban Mexico.

Table 6 presents the results of a similar simulation, but we now take each national sample and simulate moving them to urban areas on the other side of the border. To account for differences in the size of urban areas, we weight the probability of assignment to an urban area by population size. For example, a Mexican-survey respondent has a $2.2 \%$ chance of getting assigned to greater Boston, which has $2.2 \%$ of the total population in the US's hundred largest metropolitan areas. The substantial differences in urban form across the two countries result in substantial differences in predicted commute patterns for both Mexican and US urban residents. Again, this finding suggests that urban form has a relatively important role to play in predicting overall commute patterns. Although Mexican commuters certainly drive less because they have less income, our models predict a massive shift in private-vehicle commuting from $27.7 \%$ to $85.4 \%$ from moving Mexican residents to US urban areas. Similarly, although US commuters remain substantially wealthier than Mexico commuters, our models predict a fivefold increase in aggregate transit use from moving them to Mexico's urban areas. These results suggest that the US's low densities and substantial road networks contribute greatly to the country's high rates of driving in large urban areas. These differences in urban form across the border are often quite stark. For example, the hundred largest urban areas in the US have nearly ten times as much roadway per capita on average as the hundred largest urban areas in Mexico. 
Table 6. Predicted commute mode share based on actual and simulated home urban area

\begin{tabular}{lllll}
\hline Data sample & Urban form & Private vehicle & Transit & Active modes \\
\hline \multirow{2}{*}{ US population } & US cities & $89.8 \%$ & $7.1 \%$ & $3.1 \%$ \\
\cline { 2 - 5 } & Mexican cities & $64.6 \%$ & $30.3 \%$ & $5.1 \%$ \\
\hline \multirow{2}{*}{ Mexican population } & US cities & $85.4 \%$ & $11.8 \%$ & $2.8 \%$ \\
\cline { 2 - 5 } & Mexican cities & $27.7 \%$ & $49.3 \%$ & $22.9 \%$ \\
\hline
\end{tabular}

Notes: The estimations are based on Model (1) and (3) estimates that do not control for auto ownership.

Another notable finding is the shift in active transportation across the two data samples. In the US, where walking and biking represent a relatively niche commuting mode, shifting the population to Mexico's urban areas only increases the share of active commutes from $3.1 \%$ to $5.1 \%$. In Mexico, where shifting from the most to the least car-friendly urban area barely affected predicted active commute mode share, shifting the population to US urban areas results in a sharp decline in active commute share from $22.9 \%$ to $2.8 \%$. The differences in roadway per capita drives this result. Changing just this one variable results in active transportation mode share dropping to just $4.7 \%$ of all commutes. Despite the finding that Mexico's active commuters are unresponsive to shifts in urban form across Mexico's urban areas, this general finding does not hold when assigning residents to the US's much less pedestrianfriendly urban areas.

\section{Conclusion}

In this paper, we examine empirical relationships between commuters' mode choice, metropolitan urban form, and socioeconomic attributes for a five-million-respondent sample representing roughly twothirds and four-fifths of all work commuters in the US and Mexico. Focusing on how relationships vary across the border, we find several consistent takeaways with regards to urban form. In both the US and Mexico, urban residents living in housing types associated with more centrally located housing in more densely populated urban areas with less roadway are less likely to commute by car than similar residents in other housing types and other urban areas. Moreover, the strength of these relationship tends to be as strong or stronger than relationships to income or other household level attributes. Consistent with the existing literature, higher income, higher educational attainment, smaller household sizes, and greater automobile availability tend to be associated with a higher probability of commuting by private vehicle. Including automobile availability in models tends to attenuate the relationships between commuting and associated variables, like household income or educational attainment, but have less of an influence on the strength of relationships between housing type, urban form, and commute mode.

We also find several important differences across urban areas on either side of the US-Mexico border. Notably, differences in the samples' socioeconomic attributes, urban form, and commute patterns have important implications for elasticity estimates. In particular, the US's high rates of driving and generally car-friendly urban form mean that even dramatic shifts in urban form or income result in only small, predicted changes in the probability of commuting by car. From this finding, we draw three primary inferences for research into the relationship between urban form and travel behavior. First, despite being a convenient way summarize findings for meta-analyses (Ewing \& Cervero, 2010; Stevens, 2017), elasticities are not necessarily comparable across places, particularly where there are substantial differences in the distributions of the independent and dependent variables. For example, the estimated income-elasticity with respect to commuting by private vehicle is forty times stronger in Mexico than in the US. Second, despite a literature dominated by findings from US cities, elasticities estimated from 
US data are unlikely to hold outside of the US, where commute distances and the share of trips accomplished by private vehicle are unusually high. Even in the largest urban areas, which tend to be the densest and best served by transit, 90\% of US commuters use private vehicles to get work. This share barely budges by income group or urban form in all but the most densely populated metropolitan areas. Third, there remains a need for studies into the strength and direction of relationships between urban form and travel behavior from a wider variety of contexts. Academic understanding of the relationship between socioeconomic factors, urban form, and travel behavior is disproportionately weighted by findings from an extreme outlier, the United States.

In addition to the magnitude of elasticity estimates, we find several contextual differences in results from the US and Mexico. For example, women are more likely than men to commute by private vehicle in US urban areas, but substantially less likely in Mexico's urban areas. Manufacturing workers are more likely to use transit than service workers in Mexico but less likely in the US. In terms of urban form, jobs-population imbalance and jobs-land imbalance are statistically associated with mode choice in Mexico but not in the US. Overall, these results show that contextual differences likely have an important role in shaping relationships between socioeconomic factors, urban form, and travel behavior. Again, this suggests a need for great care when applying results for one context, such as the US, to another, such as Mexico.

In terms of public policy, we generally find that denser urban areas with less roadway are more likely to have a higher share of workers commuting by transit or active modes. While these relationships are relatively strong, implications for public policy are more limited, particularly in the United States, where just a handful metropolitan areas contain most of the transit and active commuters. Neither Knoxville nor Baltimore are likely to become much more like New York or San Francisco in terms of urban form. Moreover, the herculean policy efforts that would be needed to shift Knoxville's urban form to resemble Baltimore's would likely only have a small impact on overall commute mode share. In Mexico, making La Paz a bit more like Queretaro in terms of urban form, appears less of a physical challenge and more likely to result in greater shifts in mode share. Perhaps the most notable policy takeaway is that shifting Mexico's urban form to more like US urban form will likely result in substantial losses in the share of workers commuting by transit or non-motorized modes, despite Mexico's lower household incomes. In this context, it is particularly worrisome that $80 \%$ to $90 \%$ of federal and state transportation spending goes to road investments in Mexico's largest urban areas and only $7 \%$ to $11 \%$ of investments go to transit, pedestrian, or cycling investments (ITDP, 2017).

\subsection{Limitations and areas for future research}

This study relies on two large national datasets with limited spatial resolution in order to collect consistent data on commuter behavior in two different national contexts. We only know what urban area a commuter lives within, but do not know where they reside or work within that urban area. As a result, our models do not include variables related to commuters' local built environments or features, like travel cost or time, that are associated with different commute modes. Both variables are commonly included in studies of the relationship between urban form and travel behavior. While our study offers insight into how commute patterns and metropolitan urban form vary across national contexts, we have little to say about the importance of local built environments, beyond housing type as a proxy, or the role of relative travel times and costs by different modes. Moreover, there are differences in the three housing typologies and where they tend to be located within and across US and Mexican urban areas. Future research that can address these limitations across national contexts would make an important contribution to the literature and understanding of how the relationships between urban form and travel behavior vary across national contexts. 


\section{Acknowledgements}

Funding support was provided by the USDOT Tier 1 University Transportation Center "Cooperative Mobility for Competitive Megaregions" (CM2) (USDOT Award No. 69A3551747135). We would also like to acknowledge Camilo Caudillo, Juan Pablo Benitez, He Zhang, and Jialin Wang for support in data processing and management.

\section{Data availability}

Guerra, Erick, 2021. Mode choice to work in 100 largest US and Mexican urban areas. https://doi. org/10.7910/DVN/UK8PWW, Harvard Dataverse, V1, UNF:6:puGO0zsv4wyly73zzQUvHA== [fileUNF] 


\section{References}

Babyak, M. A. (2004). What you see may not be what you get: A brief, nontechnical introduction to overfitting in regression-type models. Psychosomatic Medicine, 66(3), 411-421.

Begg, C. B., \& Gray, R. (1984). Calculation of polychotomous logistic regression parameters using individualized regressions. Biometrika, 71(1), 11-18. https://doi.org/10.2307/2336391

Bento, A. M., Cropper, M. L., Mobarak, A. M., \& Vinha, K. (2005). The effects of urban spatial structure on travel demand in the United States. Review of Economics and Statistics, 87(3), 466-478. https://doi.org/10.1162/0034653054638292

Blumenberg, E., \& Pierce, G. (2014). A driving factor in mobility? Transportation's role in connecting subsidized housing and employment outcomes in the moving to opportunity (MTO) program. Journal of the American Planning Association, 80(1), 52-66.

Boarnet, M., \& Crane, R. (2001). The influence of land use on travel behavior: Specification and estimation strategies. Transportation Research Part A: Policy and Practice, 35(9), 823-845.

Boeing, G. (2017). OSMnx: New methods for acquiring, constructing, analyzing, and visualizing complex street networks. Computers, Environment and Urban Systems, 65, 126-139. https://doi. org/10.1016/j.compenvurbsys.2017.05.004

Cao, X., Mokhtarian, P. L., \& Handy, S. (2009). Examining the impacts of residential self-selection on travel behavior: A focus on empirical findings. Transport Reviews, 29(3), 359-395. https://doi. org/10.1080/01441640802539195

Cervero, R., \& Kockelman, K. (1997). Travel demand and the 3Ds: Density, diversity, and design. Transportation Research Part D, 2(3), 199-219.

CONAPO. (2018). Sistema Urbano Nacional. Retrieved from http://www.conapo.gob.mx/es/CONAPO/Datos_Abiertos_Sistema_Urbano_Nacional

Croissant, Y. (2019). mlogit: Multinomial logit models. Retrieved from https://cran.r-project.org/web/ packages/mlogit/index.html

de Vasconcellos, E. A. (2005). Transport metabolism, social diversity and equity: The case of Sáo Paulo, Brazil. Journal of Transport Geography, 13(4), 329-339.

Ewing, R., \& Cervero, R. (2010). Travel and the built environment: A meta-analysis. Journal of the American Planning Association, 76(3), 265-294. https://doi.org/10.1080/01944361003766766

Ewing, R., Hamidi, S., Gallivan, F., Nelson, A. C., \& Grace, J. B. (2014). Structural equation models of VMT growth in US urbanized areas. Urban Studies, 51(14), 3079-3096.

Ewing, R., Tian, G., Goates, J., Zhang, M., Greenwald, M. J., Joyce, A., ... \& Greene, W. (2015). Varying influences of the built environment on household travel in 15 diverse regions of the United States. Urban Studies, 52(13), 2330-2348. https://doi.org/10.1177/0042098014560991

Feng, J., Dijst, M., Prillwitz, J., \& Wissink, B. (2013). Travel time and distance in international perspective: A comparison between Nanjing (China) and the Randstad (The Netherlands). Urban Studies, 50(14), 2993-3010.

Giuliano, G., \& Dargay, J. (2006). Car ownership, travel and land use: A comparison of the US and Great Britain. Transportation Research Part A: Policy and Practice, 40(2), 106-124.

Giuliano, G., \& Narayan, D. (2003). Another look at travel patterns and urban form: The US and Great Britain. Urban Studies, 40(11), 2295-2312.

Guerra, E. (2014a). Mexico City's suburban land use and transit connection: The effects of the Line B Metro expansion. Transport Policy, 32, 105-114. https://doi.org/10.1016/j.tranpol.2013.12.011

Guerra, E. (2014b). The built environment and car use in Mexico City: Is the relationship changing over time? Journal of Planning Education and Research, 34(4), 394-408. https://doi. 
org/10.1177/0739456X14545170

Guerra, E., Caudillo, C., Monkkonen, P., \& Montejano, J. (2018). Urban form, transit supply, and travel behavior in Latin America: Evidence from Mexico's 100 largest urban areas. Transport Policy, 69, 98-105.

Handy, S., Cao, X., \& Mokhtarian, P. L. (2005). Correlation or causality between the built environment and travel behavior? Evidence from Northern California. Transportation Research Part D: Transport and Environment, 10(6), 427-444. https://doi.org/10.1016/j.trd.2005.05.002

Handy, S., Cao, X., \& Mokhtarian, P. L. (2006). Self-selection in the relationship between the built environment and walking: Empirical evidence from Northern California. Journal of the American Planning Association, 72(1), 55-74. https://doi.org/10.1080/01944360608976724

$\mathrm{Hu}, \mathrm{L}$. (2014). Changing job access of the poor: Effects of spatial and socioeconomic transformations in Chicago, 1990-2010. Urban Studies, 51(4), 675-692.

INEGI. (2015). Encuesta intercensal 2015. Retrieved from http://www.inegi.org.mx/est/contenidos/ Proyectos/encuestas/hogares/especiales/ei2015/

Ingram, G. K., \& Liu, Z. (1999). Determinants of motorization and road provision. In J. GomezIbanez, W. B. Tye, \& C. Winston (Eds.), Transportation economics and policy handbook (pp. 325356). Washington, DC: Brookings Institution Press.

ITDP (first). (2017). Invertir para movernos: Diagnóstico de inversión en movilidad 2011-2015. Versión revisada 2017. ITDP. Retrieved from http://mexico.itdp.org/noticias/invertir-para-movernos2015-diagnostico-de-inversion-en-movilidad-2011-2015/

Jaramillo, C., Lizárraga, C., \& Grindlay, A. L. (2012). Spatial disparity in transport social needs and public transport provision in Santiago de Cali (Colombia). Journal of Transport Geography, 24, 340357.

Liang, K.-Y., \& Zeger, S. L. (1986). Longitudinal data analysis using generalized linear models. Biometrika, 73(1), 13-22. https://doi.org/10.1093/biomet/73.1.13

McIntosh, J., Trubka, R., Kenworthy, J., \& Newman, P. (2014). The role of urban form and transit in city car dependence: Analysis of 26 global cities from 1960 to 2000. Transportation Research Part D: Transport and Environment, 33, 95-110. https://doi.org/10.1016/j.trd.2014.08.013

Mokhtarian, P. L., \& Cao, X. (2008). Examining the impacts of residential self-selection on travel behavior: A focus on methodologies. Transportation Research Part B: Methodological, 42(3), 204-228. https://doi.org/10.1016/j.trb.2007.07.006

Monkkonen, P. (2011). The Housing transition in Mexico expanding access to housing finance. Urban Affairs Review, 47(5), 672-695. https://doi.org/10.1177/1078087411400381

Newman, P., \& Kenworthy, J. (1989). Cities and automobile dependence: A sourcebook. Aldershot, UK: Gower Technical.

Pucher, J., Dill, J., \& Handy, S. (2010). Infrastructure, programs, and policies to increase bicycling: An international review. Preventive Medicine, 50 (Supplement), S106-S125. https://doi.org/10.1016/j. ypmed.2009.07.028

R Core Team. (2018). R: A language and environment for statistical computing. R Foundation for Statistical Computing. Retrieved from http://www.R-project.org/

Reis, J. P., Silva, E. A., \& Pinho, P. (2016). Spatial metrics to study urban patterns in growing and shrinking cities. Urban Geography, 37(2), 246-271. https://doi.org/10.1080/02723638.2015.109 6118

Stevens, M. R. (2017). Does compact development make people drive less? Journal of the American Planning Association, 83(1), 7-18. https://doi.org/10.1080/01944363.2016.1240044

Suárez, M., \& Delgado, J. (2009). Is Mexico City polycentric? A trip attraction capacity approach. Ur- 
ban Studies, 46(10), 2187-2211.

Suárez, M., Murata, M., \& Delgado, J. (2016). Why do the poor travel less? Urban structure, commuting and economic informality in Mexico City. Urban Studies, 53(12), 2548-2566. https://doi. org/10.1177/0042098015596925

Sun, B., He, Z., Zhang, T., \& Wang, R. (2016). Urban spatial structure and commute duration: An empirical study of China. International Journal of Sustainable Transportation, 10(7), 638-644.

Sun, B., Zhang, T., He, Z., \& Wang, R. (2017). Urban spatial structure and motorization in China. Journal of Regional Science, 57(3), 470-486. https://doi.org/10.1111/jors.12237

Tana, Kwan, M.-P., \& Chai, Y. (2016). Urban form, car ownership and activity space in inner suburbs: A comparison between Beijing (China) and Chicago (United States). Urban Studies, 53(9), $1784-1802$.

Train, K. (2009). Discrete choice methods with simulation (2nd ed.). Cambridge, UK: Cambridge University Press. http://elsa.berkeley.edu/books/choice2.html

Yang, J., French, S., Holt, J., \& Zhang, X. (2012). Measuring the structure of US metropolitan areas, 1970-2000: Spatial statistical metrics and an application to commuting behavior. Journal of the American Planning Association, 78(2), 197-209.

Yang, L., Wang, Y., Bai, Q., \& Han, S. (2017). Urban form and travel patterns by commuters: Comparative case study of Wuhan and Xi'an, China. Journal of Urban Planning and Development, 144(1), 05017014

Zegras, C. (2010). The built environment and motor vehicle ownership and use: Evidence from Santiago de Chile. Urban Studies, 47(8), 1793-1817. https://doi.org/10.1177/0042098009356125

Zhang, M. (2004). The role of land use in travel mode choice: Evidence from Boston and Hong Kong. Journal of the American Planning Association, 70(3), 344-360. https://doi. org/10.1080/01944360408976383

Zhu, Z., Li, Z., Liu, Y., Chen, H., \& Zeng, J. (2017). The impact of urban characteristics and residents' income on commuting in China. Transportation Research Part D: Transport and Environment, 57, 474-483. 